\title{
Exploring behaviour in the online environment: student perceptions of information literacy
}

\author{
Janice Smith ${ }^{\mathrm{a} *}$ and Martin Oliver ${ }^{\mathrm{b}}$ \\ ${ }^{\mathrm{a}}$ University College London, $U K{ }^{\mathrm{b}}{ }^{\mathrm{b}}$ Institute of Education, UK
}

\begin{abstract}
The aim of this paper is to show how information literacy can be conceptualised as a key learning process related to discipline and academic maturity, rather than as a generic skill. Results of a smallscale study including questionnaires and observation of student behaviour are reported and analysed in relation to Bruce's 'seven faces of information literacy' framework. The findings illustrate that information literacy is a highly situated practice that remains undeveloped through mandatory schooling. Some methodological issues are considered in relation to researching information literacy, including the limits of the Bruce model as a framework for analysis. We also show how decontextualised courses can foreground and privilege certain behaviours that are beneficial but that developing higher-level information literate attitudes is likely to be an iterative and contextualised process.
\end{abstract}

\section{Introduction}

As the use of the Internet and electronic resources increases, there has been a recent rise in the profile of the concept of information literacy. It is variously defined in existing literature (SCONUL, 1999; Big Blue Project, 2002) and responsibility for it ranges from its traditional roots in bibliographic instruction from library professionals to dedicated academic courses provided by information science academics (Webber \& Johnston, 2000). As more students engage with online learning, however, there is a need to ensure all students benefit from information literacy education, not just those who have access to academic or library-run courses that frequently remain voluntary.

To make the case for the need for information literacy, at a recent conference (Oxford University Learning Technologies Group, 2004) the first theme in the call

\footnotetext{
*Corresponding author. Department of Electronic \& Electrical Engineering, Torrington Place, London, WC1E 6JE, UK. Email: jsmith@ee.ucl.ac.uk
} 
for proposals asked whether we understood student behaviour relating to online resources. As Jones et al. (2004) say, little work has been done in this regard, despite a great deal of activity in the broader area of online learning. A number of studies have focused on the needs of library and information professionals or the systems development communities (Rowley, 2003), and increasingly academic-librarian partnerships are reported (McGuinness, 2003) that can sometimes be problematic (Godwin, 2003). What is currently missing from the literature, however, is any kind of educational development perspective. To begin to explore student behaviour from an educational perspective, this paper reports the results of a small-scale study that aimed to investigate an example of current information literacy provision by observing student behaviour in the online environment with a view to future enhancement. An existing taught course focusing on effective use of the Internet was analysed in relation to Bruce's (1997) 'seven faces of information literacy' framework to see whether such courses are useful in developing students' conceptions of information literacy.

This paper is structured around an introduction to information literacy and the analytic framework used, a description of the course, summaries of pre-course and post-course questionnaires, and case studies of student behaviour. The case studies and student post-course self-report lead into a discussion of what can be achieved by stand-alone courses and the benefits of contextualising information literacy education in relation to two major factors: students' home disciplines and their academic maturity.

\section{The need for information literacy}

The popularity of the Internet, and particularly the recent explosive growth in Virtual Learning Environment usage, has led to unparallelled numbers of staff using online resources in learning and teaching situations (Armitage \& O'Leary, 2003). This change in activity means both staff and students need to develop information-seeking behaviours not needed in the past, particularly in relation to quality, reliability and representativeness, given the potentially unmediated nature of online information (Walton \& Archer, 2004). The effort now going in to producing, finding and (re)using such resources has an impact on the practices of both academic staff and students. Most studies investigating information behaviour, however, stem from library and information professionals (Martin \& Rader, 2003) rather than educational researchers (Virkus, 2003). It is timely, therefore, to investigate information literacy from an educative rather than informational perspective.

For students, the world of online information in relation to their studies is a complex one (Macdonald et al., 2001). As will be seen from this study, they arrive in higher education with limited awareness of the tools and resources available to them (Rowley, 2000). Many will suffer from their lecturers' unjustified assumptions that finding and using online resources is a simple issue. A second common misconception, conceptualised as the 'Nintendo generation' (Morice, 2000, cited in Conole, 2002a) is that students' facility with technology in other domains - notably game playing-equips them with enough awareness for the rather more limited technology 
use expected in higher education. This appears to manifest itself in the abandonment of introductory computing courses (Stephens \& Creaser, 2002).

Currently, however, there are few studies that investigate the role of online resources in the learning process, although there are many that focus on access and, often, equate this to usage. While access statistics are critical from an information professional perspective (Rowley, 2003) - in terms of renewing or terminating subscriptions, or tailoring services to user needs - in terms of learning, they tell us little. The area of information studies has also undertaken work reflecting how individuals find and use information (Wilson et al., 1999). However, such studies focus on specific needs-for instance, in relation to health information - and start from an assumption that the individual has a specific information need, and this will be closely related to a particular cause, circumstance or interest, for which more is needed to be known. There is little in the area that characterises information search or use behaviour in relation to educational theory, pedagogic design or learning processes. As McDowell (2002) suggests, staff are reluctant, even in this new 'information economy', to require or value student initiative in this complex area. With pressure on academic staff to use and produce digital material (Oliver, 2003), there is, as yet, little evidence that students will persevere to find and use online resources in support of their studies.

The move to more student-centred forms of learning (Thorpe, 2002), including collaborative working in online environments, has led to a focus on situated theories of learning (Lave \& Wenger, 1991; Wenger, 1998). Work done by Becher and Trowler (2001) highlights how norms and practices vary across disciplines. Lave and Wenger (1991) describe 'legitimate peripheral participation' as a way of assimilating such practices, which suggests that they do not cross disciplinary boundaries easily. This may raise issues for information literacy education if it is conceptualised as a learning process, a form of enculturation, rather than as a set of generic skills.

To date, traditional educational theorists have not focused on the role of external resources, online or otherwise, in the learning process. Wenger, in proposing his theory of communities of practice (1998), explicitly considers artefacts, be they objects, documents or practices and shows how they become reified-representations of practice specific to particular communities. This suggests that information literacy needs to be embedded in a disciplinary context and thus is unlikely to be equally definable and applicable across a range of disciplines.

However, current approaches to the use of external resources in learning processes-loosely termed information literacy-take two forms: the checklist approach, or the stand-alone subject approach. For example, the Association of College and Research Libraries (2000) has developed a set of competency standards covering five standards and 22 performance indicators. This model implies a checklist approach through which students will demonstrate observable skills rather than knowledge or understanding, possibly just once throughout their undergraduate studies. To illustrate the second form, Webber and Johnston (2000) suggest information literacy be taught as a stand-alone subject that should be led by information 
scientists. While this approach allows students to investigate their own conceptions of information literacy, it locates the topic in the domain of information science rather than within the students' chosen discipline with, as yet, little evidence of the transfer of skills or understanding from one domain to another (Barnett, 1994).

\section{The seven faces of information literacy model}

Christine Bruce's seven faces of information literacy was a phenomenographic study with staff to understand practices in information behaviour (Bruce, 1997). She interviewed staff across a range of disciplines in Australian universities to capture their understandings of the role of information sources and produced a seven-stage model that gives a useful taxonomy whereby we can conceptualise how online resources are experienced. Her hierarchical model, ranging from technologically-orientated to wisdom-orientated positions, is reproduced in Table 1.

Little is said, however, about movement through or across the categories; nor does Bruce investigate how, when or whether staff make value judgements about the fitness for purpose of any resources they encounter. It is potentially the case that students may fit these categories too, and that their experiences of, and success in, their studies could be enhanced by a better understanding of what role and use they make of information sources-how they develop their information literacy-alongside their disciplinary knowledge.

The study described in this paper was undertaken to explore these issues in a generic, university-wide course. Specifically, the primary aim of the study was to investigate

Table 1. Christine Bruce's seven faces of information literacy

\begin{tabular}{|c|c|}
\hline Phenomenographic category & Explanation \\
\hline Information technology conception & $\begin{array}{l}\text { Information literacy is seen as using information } \\
\text { technology for information retrieval and communication }\end{array}$ \\
\hline Information sources conception & Information literacy is seen as finding information \\
\hline Information process conception & Information literacy is seen as executing a process \\
\hline Information control conception & Information literacy is seen as controlling information \\
\hline Knowledge construction conception & $\begin{array}{l}\text { Information literacy is seen as building up a personal } \\
\text { knowledge base in a new area of interest }\end{array}$ \\
\hline Knowledge extension conception & $\begin{array}{l}\text { Information literacy is seen as working with knowledge and } \\
\text { personal perspectives adopted in such a way that novel } \\
\text { insights are gained }\end{array}$ \\
\hline Wisdom conception & $\begin{array}{l}\text { Information literacy is seen as using information wisely for } \\
\text { the benefit of others }\end{array}$ \\
\hline
\end{tabular}


how students used electronic resources as they prepared a bibliography for assessment. A range of tools and electronic resources is introduced in the taught component: whether and how these are applied in practice and students' post-course conceptions of the role of electronic resources were explored through the data collection methods detailed below.

\section{Methodology}

The focus for this study was a taught elective, the 'Information Sources and How to Use Them' course available to a multidisciplinary intake across all years of study within a metropolitan, research-led institution in the United Kingdom. The course is structured around the process of finding information, using it to create a bibliography and then presenting this both on paper and via the Web. Among other things, the curriculum introduces a variety of information sources including search engines, managed hubs, gateways, bibliographic databases and image libraries. It is taught by Library and Information Studies academics and assessment is by annotated bibliography on a topic of the student's own choice, presented in paper and Web-based form and accompanied by a reflection on the efficacy - or otherwiseof the information-seeking and evaluation processes. Initially, 45 students registered for the course and 37 attended. The majority of them were first-year Information Management (IM) students (from the home department) but there was also a substantial minority from Chemistry, Biology, Linguistics and Literature, Communication Science and affiliate (Erasmus) students. All of the students from outside the home department were in years two, three or four of their programmes. (This had implications for the inferences that could be drawn, as will be discussed later.)

As a taught course requiring attendance, it appeared that access to a stable group of students, together with multiple sampling opportunities, had been negotiated. However, variable attendance was the norm as students were split into two laboratory groups and the timing of the course (in term two) meant that planned post-course interviews were not possible as students went on study leave. The small numbers involved and limited previous work in this area means the study is thus necessarily exploratory in nature.

\section{Methods}

To compliment the work done with staff (Bruce, 1997; Johnston \& Webber, 2003; McDowell, 2002), students were asked to complete pre-course and post-course questionnaires, and laboratory session observations were undertaken. The pre-course questionnaire aimed to elicit students' existing views regarding online resources while the post-course questionnaire was designed to explore whether these had changed by the end of the course. The laboratory observations were intended to supplement questionnaire data, to gain information about student activities and to be aware of any critical incidents. 


\section{Findings and discussion}

The results from the study are reported in chronological order, and have been analysed in relation to the Bruce (1997) framework to explore whether her phenomenographic categories are relevant to students. The hypothesis underlying this study is that information literacy may vary according to context; that is, a student's home discipline or year of study. This point is returned to in the case studies. Initially, however, we report on responses to a questionnaire that was developed for use before the course began.

\section{Students' preconceptions of information literacy}

The pre-course questionnaire sought some limited demographic data, relating to home discipline and year of study. As the course is an elective, three questions were included asking whether students had read the aims and objectives of the course and which of these they considered most and least important. The questionnaire was emailed to students who had registered for the course before the Christmas break and, even with two reminders, achieved only a $25 \%$ response rate. Two questionnaires were returned on paper rather than emailed-this may point to a skills deficit for some students. Worryingly, despite this course being an elective, only three students admitted to having read the aims and objectives. Two open-ended questions allowed students to explain in their own words how they would go about tackling the module's assessment task (the production of an annotated bibliography), with a focus on the resources they would use, and further to explain why they thought this would be a good way to tackle the assignment. In response to the 'how' question, the responses showed a limited awareness of electronic resources. One source of electronic information was cited three times: the library, followed by two mentions for Google. Two students were less specific, mentioning the Internet in general or else company websites. Only two students cited specific academic tools-SciFinder, Science Direct and Athens. Both were from Chemistry.

Clearly, not only was respondents' awareness of resources limited, there was also evidence of confusion as to what constitutes an electronic information source. Neither Google (a search engine) nor Athens (an access/authentication system) technically - fit this category, but the students seemed unable to discriminate between the access method and the information itself. One student mentioned 'company websites', indicating that not only is there confusion over sources of information, but distinctions between types of material (promotional versus academic) are not necessarily well understood either.

The 'why' question, addressing the students' information behaviour, again elicited limited and simplistic responses. The most popular explanations were awareness and ease of use: 'they're the ones I know of', which was given in relation to Google and the library. Illustrative of the difficulties the students faced, which became apparent in the observations, Figure 1 shows how unhelpful a standard interface is in supporting students as they develop their information literacy. All the feedback focused on 


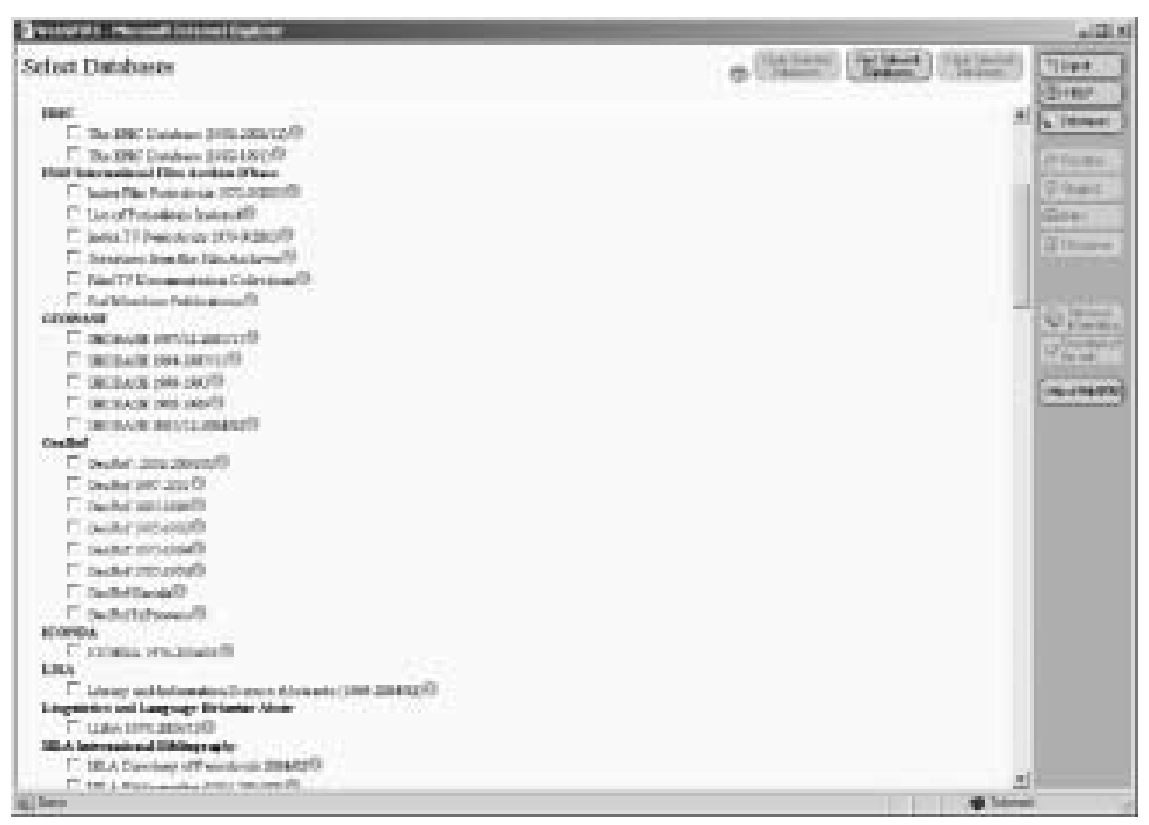

Figure 1. A screenshot from library pages showing database subscriptions

one issue - they do not know what ERIC, MLA or ICONDA are-and all any of the students could say is, 'where do I start?'.

When we consider issues surrounding ease of use, the immediate contrast between Figures 2 and 3 give us a powerful indication of the charm of basic Web searching versus the conceptual difficulties facing students accessing more sophisticated tools.

The JSTOR interface is instructive in terms of supporting learners. For those new to independent information searching, it is illuminating to look at the assumptions made: a familiarity with Boolean searches, with the concept of database fields, and of the journals in specific subject areas. Without this grounding it is easy to see why students revert to simple and familiar tools. These issues are returned to in the case studies.

In the pre-course questionnaire, it was interesting to note that only three students made a value judgement about the resources they had cited: one from IM who noted the accuracy of the library, and the two Chemistry students who appreciated the quality of the scientific databases noted earlier.

SciFinder is better than other science programs because it has a larger and more complete database.

\section{Summary of pre-course questionnaires}

Responses to this question were, on the whole, very simplistic. Given the traditional age of entry of most students for this course, many of whom have a computing-related qualification (often at 'A'-level), it is useful to see what the National Curriculum 


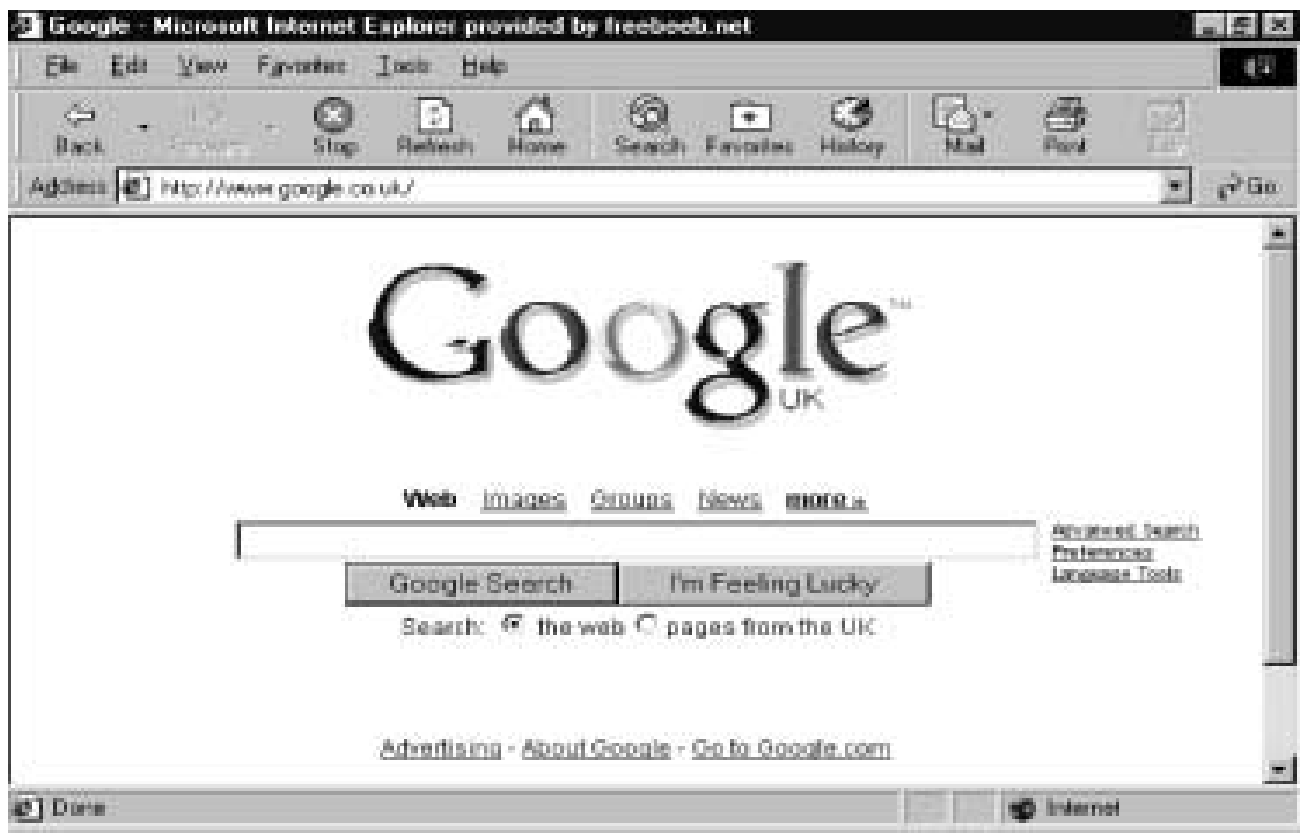

Figure 2. The Google basic search interface—simple and elegant

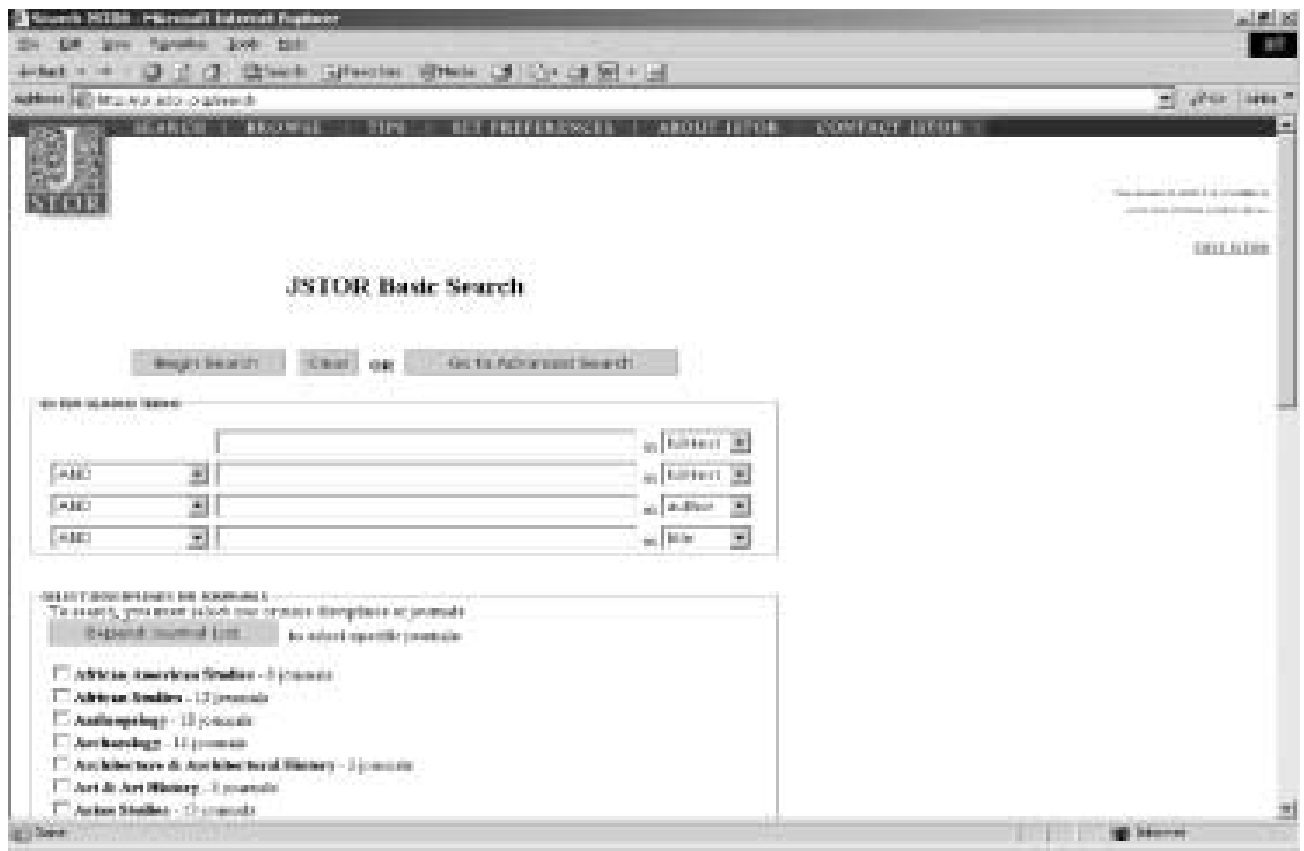

Figure 3. The JSTOR basic search interface-more challenging for novices than Google 
requires. The syllabus is clear about developing skills and attitudes in relation to information finding and expects pupils to experience and evaluate information from a range of sources. From the pre-course questionnaires, it is clear that either they do not have this experience, or they forget it before they reach university. It is reassuring, however, that some students were making value judgements of the information they accessed, even if these were in the minority before the course.

\section{Case studies}

Five observations of laboratory sessions were made across the 12-week term when the focus was on information finding. These case studies arise from observations of student behaviour and concerns as they experienced the course. The aim was to see whether the students displayed behaviour and/or attitudes that fitted the Bruce framework. Analysis of field notes shows that, of the behaviours observed, several cases emerged that illustrate the Bruce categories. The observations also uncovered important issues for consideration in developing information literacy.

\section{Case study 1: lecturers' unjustified assumptions}

Two fourth-year Chemistry students were amazed by the nature and quality of information available to them by using the refined search techniques demonstrated in the course, both on the Web and through specialist library/e-journal services. In their third year, Chemistry students undertake a project that is essentially a literature review of a topic of interest to lead them into their wet chemistry project in their final year. The range and quality of resources available were a real revelation to these students and they were quite outraged that they had not been shown how to search effectively in earlier years. Given that only the top $20-25 \%$ of students continue to a fourth-year M.Sci degree, it is instructive to note that they both remarked that they had found their literature projects challenging and time-consuming. They wished they had known about some of the techniques that were made explicit through this course earlier in their academic careers. Students in this area could be seen as holding both 'information process' and 'knowledge construction' orientations:

This course helped me to find all the information I needed for my projects and not only for my degree but for all other information I need in my life-I know where to look.

I am going to use all I have learned for my graduating thesis research and for my future employment.

\section{Case study 2: the reversion to Google}

Despite being introduced to a wide range of useful tools and sources-which they appeared to enjoy and spent some time exploring-many of the students were observed reverting to Google as their primary search tool. These students seemed to lack any perseverance with the less familiar interfaces or techniques demonstrated. Interestingly, they were all in years one and two of study. Persevering with the 
specifically academic sources used in this course appears to be related to their academic (rather than chronological) maturity. When asked about their behaviour, the students responded that they preferred Google or found it easier to use. As seen in Figures 2 and 3, the more academic tools and resources make certain assumptions that do not appear to have been dealt with by this stage of the students' education.

Being earlier in their undergraduate careers, they had yet to meet the issues that the chemistry students (in case one) had confronted. The students reverting to Google may be characterised as being at the 'information sources' end of Bruce's spectrum. This behaviour was observed many times during the in-class observation, but from the post-course questionnaires it seems all students who responded were familiar with Google before the course and now recognised that they needed to look beyond this tool:

The most important thing I have learned is that when I plan to research-I should look beyond Google and the main commerical search engines.

\section{Case study 3: the quality/quantity dichotomy}

A fourth-year Chemistry student articulated his dissatisfaction with Google search results. Typing in the general topic of his project was giving him hundreds of hits, and he was rightly dubious about the quality and provenance of some of the information he was finding. When introduced to PSIgate (the physical sciences hub funded through JISC and accessed through the RDN) he tried the same search-and was disappointed to turn up only two hits. Initially, a large information base can be reassuring to students. However, the difficulties of managing and evaluating large quantities of new information can encourage students to focus on a much smaller, but quality-controlled, literature base. This student had not contemplated this dichotomy and was not familiar with the process of follow-up techniques such as using citation indexes. He took some persuading that sometimes less is more. The idea of refining his search criteria to specific and more credible domains was immediately of interest but also challenging as there seemed to be a lot less information available. This student could be categorised as an 'information control' student, trying hard to master the information landscape for his discipline. Others-in the post-course questionnaire-commented along similar lines:

I have learned the structure of journals ... I have learnt to broaden my horizon ... I have learned how to control the area I am searching in.

I was pretty much used to using internet search engines ... electronic journal databases were quite a new thing to me and they helped me to find better quality references for all the courses I'm doing.

\section{Case study 4: the persistence of the information technology conception}

From observations and post-course questionnaires, it seems this course has influenced information-seeking and use behaviour. Most responses and observed behaviour show that students were actively using techniques and tools that had been demonstrated to 
them, and post-course most students reported positive experiences that they felt would transfer to other subjects or tasks. Given the focus of the course on information sources, a small minority, however, seemed to display what Biggs' (2002) theory of constructive alignment calls pre-structural knowledge: the students had missed the point.

Nothing on this course was new to me as I have studied html and site design for many years. (First year, IM)

It would be great if talk more about computer language. (Third year, Human Sciences)

These comments show that some students remain focused on driving the technology even when much more qualitative, complex and potentially judgemental issues are being stressed. Interestingly, the Human Sciences student also asserted that the course had taught him to surf the Internet and to find books in the library. This may point to issues in his home discipline but may also illustrate how long it may take (i.e. beyond a one-term course) for some students to shift attitude and behaviour in this domain.

\section{Case study 5: the tacit nature of information literacy}

One student, a first-year IM student, stood out from the group. In terms of search technique, the course probably taught her nothing. From day one she was adept and focused. Interestingly, she had never taken a GCSE or A-level in any IT or computing-related discipline. In Kolbian terms, however, she was a convergent thinker, with an innate curiosity about 'information'. (Kolb's [1984] application of his action leaning cycle to disciplinary epistemologies identifies convergent and divergent thinkers who will succeed or fail-relatively speaking - depending on the relationship between their learning style and their disciplinary choice.) This student, having mastered the skills and with an appreciation of the information landscape, uses the course in a way that fits well with Bruce's 'knowledge extension' category:

Databases ... Learnt where to search for specialist subject areas. I found the actual location (i.e. URLs) and identification of information sources ... very useful. However, the techniques for using them I found obvious and self-explanatory.

However, she was utterly unable to articulate how and why this area interested her, or how she had learned such sophisticated search techniques. We can view this student as having been 'enculturated'-as described by Wenger (1998) where, through participation in communities of practice, learning takes place through assimilating the tools and practices of that community. Clearly she had not learnt formally through the national curriculum. This case may show the value of informal, situated learning that has been devalued by the move to specific and measurable outcomes in school-based IT, which now may be limited to the functional at the expense of any form of enculturation.

\section{Case study summary}

These five case studies illustrate that students hold multiple perspectives on the Bruce spectrum: from information technology to sources, process, control, knowledge 
construction and extension categories. Limited responses to the pre-course questionnaire make direct comparisons difficult but it is clear from observations that the students were, mostly, confronting issues in the information sources domain leading to more sophisticated and/or critical uses of information.

\section{Attitudes to developing information literacy}

The post-course questionnaire achieved a $79 \%$ rate of return as it was administered in class time. Again, apart from some limited demographic data (to align with precourse questionnaires and observations), the students were asked open-ended questions to allow them to focus on what was taught through the course that had been most useful or valuable to them. The questionnaire followed the same format as the pre-course instrument and asked students the following:

- Please describe what you have learned on this course. Please focus on which sources were new to you and how (or whether) you have found these sources useful.

- Please describe how you might use what you have learned during this course in the remainder of your degree studies, and why this might be so.

- Any other comments about electronic resources in general?

These data are summarised in Table 2 . The comments made have been categorised, rather than the students, reflecting how each individual can belong to more than one of the Bruce phenomenographic categories. This shows that the experience of online resources is a complex issue, rather than being a one-to-one correspondence between observed behaviour and an expressed view of resources. Clearly the course has influenced behaviour if these results are compared with the on-entry questionnaire, with students offering insights from a wider range of experiences and perspectives. The results in Table 2 are split between students in their first/second years and third/fourth years of study as, from observational data, this appeared to be the key difference between how these groups of students

Table 2. Student post-course perceptions of information literacy

\begin{tabular}{lcc}
\hline Phenomenographic category & $\begin{array}{c}\text { First-year and second-year } \\
\text { students }\end{array}$ & $\begin{array}{c}\text { Third-year and fourth-year } \\
\text { students }\end{array}$ \\
\hline Information technology & $18 \%$ & $36 \%$ \\
Information sources & $87 \%$ & $63 \%$ \\
Information process & $62 \%$ & $82 \%$ \\
Information control & $6 \%$ & $18 \%$ \\
Knowledge construction & $31 \%$ & $54 \%$ \\
Knowledge extension & $6 \%$ & $0 \%$ \\
Wisdom conception & $0 \%$ & $0 \%$ \\
Value judgements & $31 \%$ & $9 \%$ \\
\hline
\end{tabular}


experienced the course. The results are given in percentages to ameliorate the problems of differential numbers of students from each year or course of study.

What these results show is that, when explaining in their own words, the students reveal that they hold multiple perspectives. Consequently, while their responses and behaviour fit into the Bruce framework, it is not possible to categorise them in relation to just one conception. In other words, this study has demonstrated that Bruce's categories cannot be used to delineate 'types' of students.

It is surprising to find that academically more mature students are more IT-focused than their younger counterparts, but it may be that they have viewed this area in a particularly IT-driven way for longer and thus, for students in later years, more sophisticated information literacy attitudes may take longer to develop. Some of the differential between the two groups in the 'control' and 'construction' categories may be explained by the fact that the younger students are predominantly experiencing this course in the context of an information management environment, whereas nonIM students clearly focus more on process and control. Third-year and fourth-year students will, by necessity, be more concerned with managing information than academically less mature students and-from comments categorised as 'knowledge construction'-focus far more on applying information in their own disciplinary context. From observations, these students were more focused on information searching for topics very closely related to the object of their disciplinary studies, whereas the first and second years appeared to be investigating a wider range of subjects.

Given the small numbers involved, the appearance of one student in the 'knowledge extension' category gives a $6 \%$ return. This end of the Bruce spectrum can easily be seen to be beyond the expectations of an undergraduate curriculum but clearly this student stood out from her peer group. What may deserve more attention is the students reporting any kind of value judgement after undergoing the course. The attention given to 'information overload' (Conole, 2002b) suggests that an ability to evaluate the quality of online resources is key to enhancing student performance in this area. Prior to the course, few students made reference to this aspect of information behaviour, and the proportion commenting on this issue in the post-course questionnaire remains low. The Bruce (1997) study does not deal with this issue, although it may be implied by her 'wisdom' conception. However, an evaluation of fitness for purpose (i.e. a value judgement) is qualitatively different from the notion of using information wisely. This accords well with Macdonald et al.'s (2001) findings on the different experiences of undergraduate and postgraduate students. If an aim of any kind of information literacy education is to ensure that students become critical consumers of information, the proportions reported in Table 2 may be interpreted as being quite low. Consequently, this area may benefit from reinforcement in the course.

The primary objective of the course is to teach students to search the Internet efficiently and effectively. Clear majorities of both groups of students comment that the course achieved its aims, as can be seen in the striking increases in awareness across the 'sources' and 'process' categories post-course, presented in Table 3. 
Table 3. The number of student comments indicating an increase in understanding regarding information sources and search processes

\begin{tabular}{lccccc}
\hline & $\begin{array}{c}\text { First-year and second- } \\
\text { year students }\end{array}$ & & \multicolumn{2}{c}{$\begin{array}{c}\text { Third-year and fourth- } \\
\text { year students }\end{array}$} \\
\cline { 2 - 3 } Phenomenographic category & Pre-course & Post-course & & Pre-course & Post-course \\
\hline Information sources & 4 & 14 & & 2 & 7 \\
Information process & 0 & 10 & & 1 & 9 \\
\hline
\end{tabular}

The results in Table 3 are encouraging in so far as this existing course is clearly meeting its aims and objectives. However, it does show the difficulties of analysing an existing course in relation to a framework that did not guide its development, as can clearly be seen by the results reported in Table 2. Activities were not necessarily provided within the course to demonstrate all the Bruce categories, but the sources and processes that were the focus of the course illustrate their success in Table 3. Nonetheless, the results also indicate that the Bruce framework may have value for those charged with designing and developing courses in information literacy education, to ensure that possibilities for development are provided in all of the categories.

\section{Summary of post-course questionnaire}

What has become clear through this study is that the Bruce framework is a useful analytical model in terms of its relation to theories of learning and as a guide to pedagogic design for courses of this nature. However, the open-ended nature of the questionnaire and the student responses to it have shown a weakness in relation to the model: the defining boundaries between the categories are very fine, potentially very blurred. For instance, occurrences of the term 'database' have been problematic as sometimes this appears to refer to databases as a tool or technology, while in other cases its use appears to refer to sources.

There does appear to be a qualitative difference between the disciplinary context of students and the way they experience the course. Two things suggest themselves here. First, that information literacy is an iterative process closely related to the object of study where a just-in-time approach may be useful to students from other disciplines. Second, that information management students may need the value judgement aspect of information searching and use reinforced through other aspects of their studies. Although the numbers involved are quite small, there appears to be a qualitative difference between the academically less and more mature students. This may be explicable by the wider framework of the students-the IM degree (of which most of the first-year and second-year students were part) considers these issues from a broad perspective. Students from other disciplines, however, may be subsuming what is learned on this course directly into their disciplinary studies where the enculturation 
process may ensure that discrete value judgements about the quality of sources are less of a focus.

\section{Conclusions}

The hypothesis that information literacy is a highly-situated practice that will vary across disciplines appears to be supported by this study. Physical science students accessed and used a range of discipline-related resources, whereas information management students used resources related to a wider range of topics. The course did not seek to define information literacy, choosing instead to focus on an application of a well-respected framework (Bruce, 1997). The course uses a constructivist approach to learning and teaching whereby students negotiate a topic of their own choosing on which to be assessed. This allows for a broad view of information sources and processes to be developed. What is interesting, however, is that the desire to develop their information literacy was, in this instance, related to the academic maturity of the students.

There is little doubt that students arrive on this course with a very limited awareness of the high-quality, specialised resources that are available on the Internet. They have poor search techniques and display poor use of bookmarks for organising information. By the end of the course, however, students were using a wider range of sources and techniques to access and organise their information sources. Many could also see the applicability of what they had learned to their wider studies, and several concurred with the notion that:

I am able to find relevant information much more quickly.

Even given the students' favourable view of information literacy, there are clearly issues of interest to online resource and human-computer interaction designers from this study. The students do not approach the assessment task from a library and information professional view of categorising resources, and some common tools and interfaces make too many assumptions about students' existing skill levels. Furthermore, it would be interesting to follow-up the academically less mature students to see if the course proves beneficial in their later years of study, in the ways remarked by the chemistry students who clearly felt they would have benefited from this knowledge earlier. This investigation of existing information literacy education provision has, therefore, highlighted issues of disciplinary difference in what is thought to be a generic course. These issues give clear goals to enhancing future provision by redesigning the teaching of information literacy to include a more situated aspect.

Bruce's (1997) phenomenographic categories do seem to be a useful way to interpret students' information literacy levels but clearly have their limitations. Not only can the boundaries between categories become blurred as students relate their experience, but the students also demonstrate multiple perspectives. Those charged with the design of information skills/information literacy courses may find this framework useful, as it suggests pedagogic designs and learning and teaching strategies most likely to support students in developing their information literacy. 
The emphasis in this course was on finding and using information. The evaluative element of information literacy does not appear to be as well developed, although it is implied through the use of certain tools and techniques, but may benefit from being more explicit. However, the findings from this study also suggest that such decontextualised courses may focus on specific aspects of the Bruce framework such as sources and process, while not catering for the higher-level understanding we may wish to encourage.

\section{Acknowledgements}

Thanks go to Susan Hockey and Vanda Broughton from the School of Library, Archive and Information Studies at UCL, who facilitated this study.

\section{References}

Armitage, S. \& O'Leary, R. (2003) A guide for learning technologists, e-learning series No 4 (York, LTSN Generic Centre). Available online at: http://www.ltsn.ac.uk/ (accessed 29 April 2004).

Association of College and Research Libraries (2000) Information Literacy Competency Standards for Higher Education. Available online at: http://www.ala.org/acrl/ilintro.html (accessed 29 April 2004).

Barnett, R. (1994) The limits of competence (Buckingham, SRHE/Open University Press).

Becher, T. \& Trowler, P. R. (2001) Academic tribes and territories (2nd edn) (Buckingham, SRHE/ Open University Press).

Big Blue Project (2002) The Big Blue: final report. Available online at: http://www.library.mmu.ac.uk/ bigblue/finalreportful.html (accessed 21 October 2004).

Biggs, J. (2002) Aligning the curriculum to promote good learning, paper presented at the Imaginative Curriculum Symposium. Available online at: http:/www.ltsn.ac.uk/application.asp?app=resources.asp\&process=full_record\&section=generic\&id=167 (accessed 12 January 2004).

Bruce, C. (1997) The seven faces of information literacy (Adelaide, Auslib Press).

Conole, G. (2002a) The evolving landscape of learning technology, ALT-f, 10(3), 4-18.

Conole, G. (2002b) Systematising learning and research information, fournal of Interactive Media in Education, 7. Available online at: http://www-jime.open.ac.uk/2002/7/ (accessed 17 May 2004).

Godwin, P. (2003) Information literacy but at what level?, in: A. Martin \& H. Rader (Eds) Information and IT literacy: enabling learning in the 21st century (London, Facet Publishing).

Johnston, B. \& Webber, S. (2003) UK academics' conceptions of the Information Literate University (ILU): emerging findings, paper presented at the SRHE conference, London, December.

Jones, C., Zenios, M. \& Griffiths, J. (2004) Academic use of digital resources: disciplinary differences and the issue of progression, Proceedings of Networked Learning 2004, Lancaster. Available online at: http://www.shef.ac.uk/nlc2004/Proceedings/Symposia/Symposium9/ Jones_et_al.htm (accessed 29 April 2004).

Kolb, D. A. (1984) Experiential learning: experience as the source of learning and development (New Jersey, Prentice-Hall).

Lave, J. \& Wenger, E. (1991), Situated learning: legitimate peripheral participation (Cambridge, Cambridge University Press).

Macdonald, J., Heap, N. \& Mason, R. (2001) 'Have I learnt it?' Evaluating skills for resource-based study using electronic resources, British fournal of Educational Technology, 32(4), 419-433. 
Martin, A. \& Rader, H. (Eds) (2003) Information and IT literacy: enabling learning in the 21st century (London, Facet Publishing).

McDowell, L. (2002) Electronic information resources in undergraduate education: an exploratory study of opportunities for student learning and independence, British fournal of Educational Technology, 33(3), 255-266.

McGuinness, C. (2003) Attitudes of academics to the library's role in information literacy education, in: A. Martin \& H. Rader (Eds) Information and IT literacy: enabling learning in the 21st century (London, Facet Publishing).

Morice, J. (2000) Skills and preferences: learning from the Nintendo generation, International Workshop on Advanced Learning Technologies: Design and Development Issues (Palmerston North, NZ, IEEE).

Oliver, M. (2003) Rethinking the reuse of electronic resources: contexts, power and information literacy, Fournal of Interactive Media in Education, 1. Available online at: http://wwwjime.open.ac.uk/2003/1/ (accessed 29 April 2004).

Oxford University Learning Technologies Group (2004) Shock of the Old 4 Conference Call for Proposals. Available online at: www.oucs.ox.ac.uk/ltg/events/shock (accessed 29 April 2004).

Rowley, J. (2000) User behaviour monitoring and evaluation framework (Bristol, JISC).

Rowley, J. (2003) Profiling and understanding student information behaviour: methodologies and meaning, $A L T-\mathcal{F}, 11(1), 28-40$.

SCONUL (1999) Information skills in higher education: a SCONUL position paper (London, SCONUL).

Stephens, D. \& Creaser, C. (2002) Information science student IT experience and attitude toward computers: results of a five year longitudinal study, Italics, 1(2). Available online at: http:// www.ics.ltsn.ac.uk/pub/italics/issue2/dstephens_b/005.html (accessed 29 April 2004).

Thorpe, M. (2002) From independent learning to collaborative learning: new communities of practice in open, distance and distributed learning, in: M. R. Lea \& K. Nicoll (Eds) Distributed learning: social and cultural approaches to practice (London, RoutledgeFalmer).

Virkus, S. (2003) Information literacy in Europe: a literature review, Information Research, 8(4). Available online at: http://informationr.net/ir/8-4/paper159.html (accessed 21 October 2004).

Walton, M. \& Archer, A. (2004) The Web and information literacy: scaffolding the use of web sources in a project-based curriculum, British fournal of Educational Technology, 35(2), 173-186.

Webber, S. \& Johnston, B. (2000) Information literacy: new perspectives and implications, fournal of Information Science, 26(6), 381-397.

Wenger, E. (1998) Communities of practice: Learning, Meaning and Identity (Cambridge, Cambridge University Press).

Wilson, T. D., Ellis, D., Ford, N. \& Foster, A. (1999) Uncertainty in information seeking: final report to the British Library Research and Innovation Centre. Available online at: http://informationr.net/tdw/publ/unis/ (accessed 29 April 2004). 